\title{
Erratum to: Role of the aryl hydrocarbon receptor in carcinogenesis and potential as an anti-cancer drug target
}

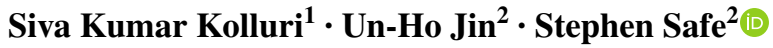

Published online: 11 July 2017

(c) Springer-Verlag GmbH Germany 2017

Erratum to: Arch Toxicol (2017) 91:2497-2513
DOI 10.1007/s00204-017-1981-2

Acknowledgement of some grant support is inadvertently missed in the publication and corrected as below.

Acknowledgements Grant support of the National Institutes of Health (P30-ES023512, R01-ES025839, R01-CA202697, R01-ES016651), Texas AgriLife Research, the Sid Kyle endowment and The American Cancer Society (RSG-13-132-01-CDD) are gratefully appreciated.

The online version of the original article can be found under doi:10.1007/s00204-017-1981-2.

Stephen Safe

ssafe@cvm.tamu.edu

1 Department of Environmental and Molecular Toxicology,

Oregon State University, Corvallis, OR 97331, USA

2 Department of Veterinary Physiology and Pharmacology, Texas A \& M University, 4466 TAMU, College Station, TX 77843, USA 